\title{
TAKTING THE PARADE OF TRADES: USE OF CAPACITY BUFFERS TO GAIN WORK FLOW RELIABILITY
}

\author{
Iris D. Tommelein ${ }^{1}$
}

\begin{abstract}
The Parade of Trades game introduces concepts of sequential dependence and process variability in order to illustrate the detrimental impact such variability has on a system's performance. In this paper we refer to the Parade of Trades to explore the use of capacity buffers in order to improve system performance as is done, for example, when developing a takt plan. Using discrete-event simulation as a discovery tool to study alternative means of work structuring, we here present an augmented Parade of Trades model in which standby capacity is available to make up for any insufficiency in completing work relative to what needs to be completed in any given takt. The judicious provision of standby capacity can help to gain work flow reliability. The design of production systems using standby capacity is barely mentioned in the construction literature. We start to shed light on this design question in this paper. The discussion of the model's results expands on the distinction between using standby capacity vs. outright adding capacity. This distinction is important to understand in the context of work flow reliability as well as continuous improvement based on Lean thinking, and should spark good follow-on discussion!
\end{abstract}

\section{KEYWORDS}

Parade of Trades, dependence, variability, capacity buffer, process capability, takt planning, discrete-event simulation

\section{INTRODUCTION}

Interdependence and uncertainty have for the longest time been hampering and will continue to hamper construction industry performance. They are well-documented industry challenges (e.g., Crichton 1966). A challenge with improving performance is lack of recognition of the challenges, as well as lack of knowledge and practical application of principles and methods to tackle them.

To develop students' and practitioners' understanding of interdependence and variability and its impact on production system performance Greg Howell developed, more than 20 years now, a hands-on simulation game inspired by Goldratt and Cox (1986). The aim of playing the game is to teach the concept of work flow reliability, where work flow is expressed by the number of units of work that get passed from one construction trade to the next. The game is based on a simple linear sequence of sequentially-dependent process steps with hand-offs from one step to the next determined by the roll of a die,

Prof., Civil and Envir. Engrg. Dept., Director, Project Production Systems Lab., Univ. of California, Berkeley, CA 94720-1712, USA, tommelein@,berkeley.edu, orcid.org/0000-0002-9941-6596 
thus mimicking a process subject to variability. We called it the Parade of Trades and studied it in greater detail using computer-based discrete-event simulation (Tommelein et al. 1998, 1999).

Once participants have finished playing the game, they are encouraged to reflect on the results their Parade obtained while considering the die they played with. This serves as a segue into exploring Lean concepts, principles, and methods. In the ensuing discussion, participants will likely suggest topics and means to improve system performance, some more traditional and some more in line with Lean thinking. Examples of such topics or means are the difficulty and importance of being able to commit a priori to a project end date to a customer, the value of reducing variation (i.e., the manifestation of variability) in the system, the willingness (or not) to pay more for a die with less variability (greater reliability), the use of time and inventory buffers to allow for maximization of resource utilization, and the possibility of restructuring work by allowing trades to help other trades that are performing adjacent steps (a kind of multi-skilling). In such discussions, participants often find themselves mired in the desire to maximize resource utilization. They tend to equate that to the optimization of productivity but these are not the same (e.g., see Ballard 1999). That there may be a desirable trade-off between optimizing utilization vs. optimizing other system objectives can come across as heresy. The game host then has to put in effort to open up participants' mindsets so that they can begin to consider alternative production system designs to make that trade-off.

In contrast to promoting a single-minded productivity focus, Lean thinking focuses first on describing the value stream and determining its length (duration), then on improving steps in that value stream to make it shorter in length while also improving the steps themselves to make them better. A foundational book describing this Lean thinking is Rother and Shook's (1998) "Learning to See." A book further describing system tradeoffs, is Modig and Åhlström's (2012) "This is Lean.” Methods that implement Lean thinking support going back-and-forth between improving the system characteristics (e.g., throughput) vs. component characteristics (e.g., point speed). In line with this Lean thinking, in this paper we explore the use of capacity buffers to improve system performance as is done, for example, when developing a takt plan.

The following section presents a selection of papers from the construction engineering and management literature including mainly studies of enhancements made to the Parade of Trades, strategies to cope with variability, and a few key references on the use of capacity buffers in construction, specifically in takt planning. Section 3 describes a new discrete-event simulation model that enhances the Parade of Trades by takting it. Section 4 presents simulation results, comparing three alternatives models. It is followed by a discussion section and conclusions.

\section{RELATED LITERATURE}

Since the Parade of Trades was introduced as a teaching tool for Lean construction in the late 1990s, it has become not only a widely-used exercise in class-room and practitionertraining settings, but also a reference system for further study by scholars around the world. Enhancements have been made to the game by modifying some of its inputs and parameters, adding various modelling dimensions, and coding it in computer software. Several researchers replaced the roll of a die with another probability density function in their models, possibly more so for pragmatic reasons (e.g., using a triangular probability density function readily available in the simulation engine they used) rather than grounded in conceptional need since the simulation with die rolls was intended to serve 
as a discovery tool. Alarcón and Ashley (1999) added inventory buffers and studied how their use affects a trade's throughput and the project's duration and cost. AbbasianHosseini et al. (2018) argued that variability varies from one trade to another (i.e., that each trade should have a different die) and accounted for a direct-, an indirect-, and a planning cost in their models to study where and what system improvement investments to make. Senior (2011) presented a computer model that allows for using 1 or 2 crews per trade and for limiting a trade's weekly output, but did not say exactly when or why to consider these. Han and Park (2011) implemented an online version where corrective managerial action can be taken reactively during execution using overtime or overmanning (i.e., provision of additional capacity) in lieu of developing a plan that $a$ priori includes any buffers.

The Parade of Trades lends itself to rich discussion of strategies to cope with variability in production systems. Such strategies have been mentioned in early papers on Lean construction and in many papers thereafter (too many to cite here, in literature inand also outside of construction management). Howell et al. (1993) argued for decoupling the work of trades in order to fully understand the work (their capacity), by reducing the immediacy of their interdependence defined by hand-offs of completed units of work. They suggested adding time buffers to the system and thereby allow for inventory buffers to build up before starting the follow-on trade's work. Understanding of capacity could lead to the development of standard work, and thus a reduction in variability in the amount of work (variability in quantity) that can be done in a certain amount of time. The benefits of reducing quantity variability on project duration was discussed in the original Parade of Trades paper (e.g., the benefit of using a 4-6 die rather than a 3-7 die). Also along this line, readers familiar with the Last Planner ${ }^{\circledR}$ System will recognize that buffers shield production units from upstream variability, so that trades can exercise their capacity and also work on improvements behind the shield (Ballard and Howell 1998).

Capacity buffers are much less discussed in the literature than time- and inventory buffers are. They are, however, omnipresent and crucially important in Lean production systems. They have been mentioned at times in the context of project delivery (e.g., Horman and Kenley 1998) and in Lean construction papers (e.g., Ballard 1999, Sakamoto et al. 2002, Horman et al. 2003, González et al. 2004). In fact, their use in practice in the form of overtime or overmanning is common when managers react to the manifestation of schedule delays, as mentioned among others by Han and Park (2011). What appears to not be so common in construction is designing the production system with provision $a$ priori of capacity buffers in the planning phase.

Our interest in exploring the use of capacity buffers during planning was kindled in the context of our studying the use of takt planning in construction. For instance, Frandson et al. (2015) compared and contrasted the Location Based Management System (LBMS) with takt planning (TP) and concluded that "Construction planners can use four types of buffers: (1) time, (2) capacity, (3) space, and (4) plan buffers (workable backlog). LBMS buffers with (1), (3), and (4). Time is the preferred buffer, but space is also used when work is scheduled in areas larger than what a crew requires to complete their task productively. In contrast, TP buffers with (2), (3), and (4). Capacity is the preferred buffer, accomplished through underloading. Space (zones) unoccupied by any trade during a given Takt can also serve as a buffer." Dlouhy et al.'s (2019) description of buffer management in takt planning does not expand on the use of capacity buffers.

With this literature in the background, we next formulate a plan for the Parade of Trades that uses takt. This plan illustrates how one might approach modelling the use of 
capacity buffers while designing the production system so as to ensure system performance gauged by work flow reliability.

\section{PROBLEM STATEMENT AND MODEL FORMULATION}

\section{Original Parade of Trades}

Presented for reference, in a nutshell, is the original Parade of Trades. The Parade is formed by lining up 5 trades in a linear sequence (A, B, C, D, and E); these trades perform consecutive steps in a process. The work of each trade is done step-wise (one step per time unit, e.g., one step each week), as is represented by the symbols labeled [SubA] through [SubE] in Figure 1 (these symbols are called combi activities). The objective is for each trade SubY to pass 100 units of work from BufferXY in front of them to BufferYZ following them (these symbols are called queues), and thus for the Parade to pass all 100 units from the front of the line (the input buffer, Inputa) to the end (the output buffer, CompleteE). When this has been accomplished, the project is completed.

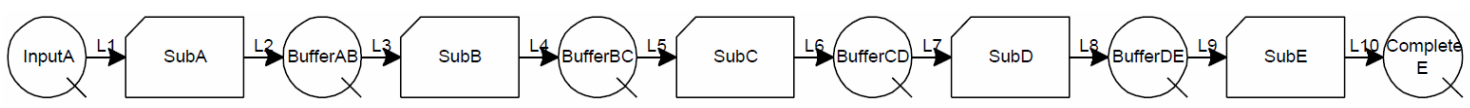

Figure 1: Parade of Trades Line-up (Figure 1 in Tommelein et al. 1998)

Variability is introduced in the simulation by having the roll of a die determine how many work units each trade can pass at a given time. After a trade has rolled her die and passed the appropriate number of units of work, she must wait until the trade downstream from her in turn has rolled her die and taken units of work from the buffer in-between them, before she may replenish this buffer. During the simulation participants collect data that they will analyse and discuss once their project has been completed. Before reading on, readers should familiarize themselves with the original Parade's details and teaching points presented in Tommelein $(1998,1999)$.

\section{TAKTed Parade of Trades}

\section{Alternative Production System Designs for the Parade of Trades}

When viewing the original Parade of Trades from a production-system design perspective, note that it depicts a push system. A teaching assignment is to ask students to redesign this model so as to implement a pull system or a ConWIP system (e.g., see Hopp and Spearman 2004) and study various alternatives of these based on a number of metrics of their choosing, e.g., work-in-process (WIP), resource utilization, and variability in project duration. Once students have gained deeper understanding of concepts of production systems design, including the fundamentals of takt planning, a follow-on assignment is to ask: How would you takt the Parade of Trades? and What metrics would you use to gauge the performance of the Parade? We address these questions by presenting a simulation model and results.

\section{Production System Design of a Takted Parade of Trades}

The rationale that supported this model's development reflects Lean thinking in the following way. A first step in Lean production system design is to eradicate all unwanted variability. Thus, if a trade were to start with a 3-7 die, they would try to improve their process so that they can replace it with a 4-6 die, or ideally with an all-5 die. This die characterizes the trade's process capability, which is defined as the probability 
distribution describing the variability in the output of a process under normal operating conditions. This distribution may need to be adjusted based on the context in which the project is delivered, if the conditions are different from normal. Assume that some but not all variability can be driven out in this case to the extent that each trade on the team ends up with a 4-6 die. The second step is to buffer against any remaining variability in order to achieve a workflow that is as reliable as attainable at the time, i.e., until the process capability can be improved further. In this step the use of capacity buffers may be considered, as will be demonstrated in the model. Subsequent steps are then to continue to improve this system's performance.

Figure 2 shows an excerpt of a Parade model that is structured for work to be executed according to the expectations set forth when developing a takt plan. The combis and queues (all shown in white) in Figure 1 are replicated (likewise in white) in the takted model (Figure 2). Their names changed slightly, but they are basically the same, e.g., focusing on the work of trade B, Figure 1 shows the sequence BufferAB - SubB Buffer BC whereas Figure 2 shows the sequence AtoB - BPasses - BtoC. The combis and queues shown in blue in Figure 2 depict the logic of how the takted model works, as is explained later. The page limit of this paper prevented us from including the entire model but in essence the model replicates for each trade what is shown here for trade B.

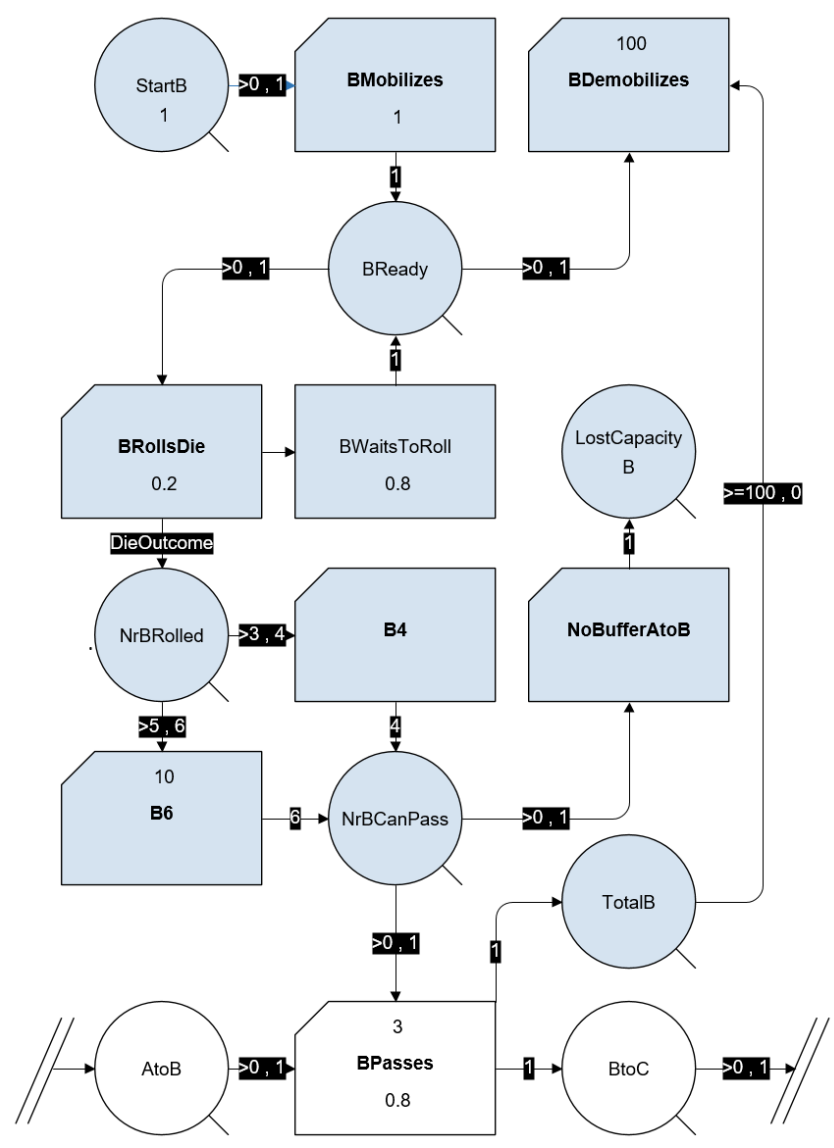

Figure 2: Takted Parade of Trades - Excerpt of EZStrobe Model Detailing Trade B

The takt planning objective to be met and addressed in this model is that a certain quantity of work associated with each step in the Parade is guaranteed to be done within the takt allowed for it. Here, the takt is set to be one week (it could be another fixed time unit). In 
this way, takt planning (where the term planning is understood to include execution as well) enforces the discipline of creating and achieving reliable hand-offs.

A number of alternative means exist to structure the work (including determining the takt) in order to establish a takt plan. The model here allows for the use of standby capacity to mitigate any manifestation of variability in capacity that might negatively affect a trade's performance relative to what they committed to. As in the original Parade, that capacity is determined by the roll of a die. The figures and data in this paper stem from the use of a 4-6 die by all trades, per the rationale provided previously. Note that this discrete probability density function is easily changed to any other function (discrete, normal, triangular, beta, etc.) for any one trade individually or for all trades.

In contrast to the original Parade, which had trades "commit" only to an average level of performance, it is assumed here that the takt plan is developed with each trade committed to passing at least 5 units of work each week (passing more units if possible is acceptable, but not less). That is, the takt is set at 5 units per week. Given that the trade's capacity is known to be either 4 or 6 units per week (on average 5), when rolling a 4, the trade must make up for the shortfall and deploy an extra unit of capacity. That is, the trade must have capacity on standby and, as per its definition, this capacity will be used when needed and remain unused otherwise.

In practice, standby capacity can be provided in several ways. Projects that implement takt planning may require a trade that does not complete their 5 units in a given takt (assume that the takt is set at a 5-day week, for example) to either have someone stepping in to help in the course of that week (possibly a crew foreman), work overtime at the end of a work day during that week, or work on the weekend to fulfill their commitment. Whether this is or isn't on the trade's own dime will depend on how the commitment was defined and whether the trade had full control over the work they committed to.

\section{Modeling Constructs for the Takted Parade of Trades}

The modeling constructs used for takting the Parade are detailed next, using symbols that are explained here and further detailed in Ioannou (n.d.) and Martinez (1996). At the top of Figure 2 is the combi [BMobilizes] showing that trade B, of which 1 unit is waiting in queue StartB, will arrive on site 1 week (assuming time units are expressed in weeks) into the project and get to queue Bready. The number under the text in a combi describes the duration of the corresponding task. Here, the duration of [BMobilizes] is 1 unit of time and it is assumed that time units are expressed in weeks. Trades mobilize on site in consecutive weeks: A arrives at the start of the project, B one week into it, C two weeks into it, etc.

The combi [BDemobilizes] shows that B leaves the site after completing 100 units of work, i.e., when the queue TotalB has $>=100$ units in it. The number above the text in a combi describes the priority of the combi over other combis that may compete to draw resource(s) from the same predecessor queue. Here, the priority of [BDemobilizes] is 100, so when it can start it will draw a resource from BReady before [BRollsDie] gets to do so.

As in the original Parade, when trade B is on site BReady, the die they roll each week will indicate their capacity to do work. The number rolled is the DieOutcome. It is computed based on a random number in the range 0 to 1 generated by the computer: if it is less than 0.5 , then the outcome is 4 , otherwise it is 6 . In the course of each week, trade $\mathrm{B}$ alternates between rolling the die [BRollsDie] and waiting to roll again 
[BWaitsToRoll]. The durations of these two combis are strictly positive and add up to 1 week; other than that, their actual values do not matter.

Given the 4-6 die, the outcome of a roll will be either 4 or 6 . The model first checks if it is 6 and, if so, the combi [B6] passes 6 units to NrBCanPass, which is a queue that defines B's capacity to do work that week. If the roll is 4 , then the combi [B4] passes 4 units to NrBCanPass.

By construction of the model, each trade always has some work to do since a preceding trade never passes 0 units. Each week, trade $B$ will take as many units from AtoB as it can to match its capacity NrBCanPass that week. If AtoB $<$ NrBCanPass, then trade B passes all units available in AtoB; otherwise trade B passes NrBCanPass. In the case of the former, trade B starves (it cannot exercise some of its capacity). Since capacity is a perishable resource, meaning that it cannot be saved for use later, the combi [NoBufferAB] will take the units remaining in NrBCanPass and add them to the LostCapacityB queue to keep track of the cumulative total amount lost.

\section{Three Scenarios of the Parade of Trades}

To study how standby capacity helps to meet the previously-stated objective of takt planning, we compared simulation results from three different scenarios of this model, and discuss the extent to which they succeed in meeting the objective of passing 5 units each week.

Scenario 1 is the original Parade where each trade uses a 4-6 die. This scenario was already presented in Tommelein $(1998,1999)$.

Scenario 2 is the takted Parade where each trade uses a 4-6 die and each trade also provides 1 unit of standby capacity to make up for below-average performance should DieOutcome turn out to be 4 . This standby capacity guarantees that the trade will pass at least 5 units each week, i.e., meet the takt. In effect, the results of this model will be identical to the results obtained when using a 5-6 die. However, the model as constructed allows for the collection of data on the use of standby capacity, from which deeper insight can be gained, as discussed later.

Scenario 3 is the original Parade where each trade uses a 5-7 die. The rationale for considering this scenario stems from the logic that, one may wonder: If 1 unit of standby capacity is made available every week as is the case in Scenario 2, then why not have that unit deployed every time it can? Restated: Why not pass an extra unit when there are extra units in AtoB (or ItoJ in general) to be passed, rather than pass an extra unit only when a 4 is rolled? The results of simulating each of these three scenarios are presented next.

\section{COMPUTER IMPLEMENTATION}

The computer model used to generate data for the three scenarios as described was implemented using the EZStrobe Version 4.18 front-end in Microsoft Visio Professional 2016, that calls the Stroboscope Simulation System Educational Version 4,0,0,0 developed by Julio C. Martinez and Photios G. Ioannou (Martinez 1996). A free educational version of this software may be downloaded from Ioannou's (n.d.) website.

\section{SIMULATION RESULTS OF ORIGINAL vS. TAKTED PARADE}

Figures 3, 4, and 5 show the models' results plotted in Microsoft Excel, focusing on three metrics: (1) how long the project will take, (2) how much time each trade will be on site to complete their work, and (3) how much of the capacity provided by a trade is lost due 
to starvation, without counting the standby capacity. The project duration metric gauges system performance of concern to the general contractor, the owner, and others. The time on site metric is of utmost concern to trades because they tend to work on many projects concurrently and sequentially, and face the challenge of managing their work force to meet the demands of all projects in their portfolio. The lost capacity metric is an indication of waste due to variability of work flow, another concern primarily for the trades.

Simulation results were obtained by replicating each scenario 100 times (a number large enough to explore variability-related concepts), and depicted as shown to illustrate the stochastic nature of the system. Scenario 1 is shown in red $\left(A_{1}, B_{1}, C_{1}, D_{1}\right.$, and $\left.E_{1}\right)$, Scenario 2 in blue $\left(A_{2}, B_{2}, C_{2}, D_{2}\right.$, and $\left.E_{2}\right)$, and Scenario 3 in brown $\left(A_{3}, B_{3}, C_{3}, D_{3}\right.$, and $\left.\mathrm{E}_{3}\right)$.

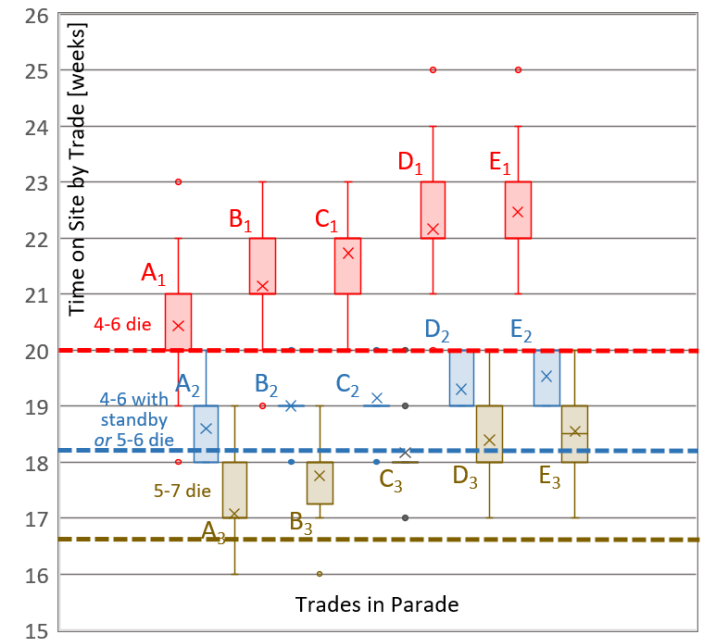

Figure 3: Box-and-Whisker Plot of Simulation Results Showing Time on Site by Trade for Scenarios 1, 2, and 3

Table 1: Simulation Results of Time on Site by Trade for Scenarios 1, 2, and 3, each Replicated 100 Times

\begin{tabular}{|c|c|c|c|c|c|}
\hline Trade & A & B & C & D & $\mathbf{E}$ \\
\hline \multicolumn{6}{|c|}{ Scenario 1: 4-6 Die (Average 5) } \\
\hline Average & 20.43 & 21.14 & 21.73 & 22.16 & 22.47 \\
\hline Std Dev & 0.93 & 0.82 & 0.76 & 0.81 & 0.73 \\
\hline Minimum & 18 & 19 & 20 & 20 & 21 \\
\hline Maximum & 23 & 23 & 23 & 25 & 25 \\
\hline \multicolumn{6}{|c|}{$\begin{array}{l}\text { Scenario 2: 4-6 Die with Standby Capacity } \\
\text { (like a 5-6 die, Average 5.5) }\end{array}$} \\
\hline Average & 18.6 & 19 & 19.14 & 19.3 & 19.53 \\
\hline Std Dev & 0.51 & 0.43 & 0.40 & 0.46 & 0.50 \\
\hline Minimum & 18 & 18 & 18 & 19 & 19 \\
\hline Maximum & 20 & 20 & 20 & 20 & 20 \\
\hline \multicolumn{6}{|c|}{ Scenario 3: 5-7 Die (Average 6) } \\
\hline Average & 17.07 & 17.75 & 18.16 & 18.39 & 18.55 \\
\hline Std Dev & 0.76 & 0.56 & 0.58 & 0.63 & 0.63 \\
\hline Minimum & 16 & 16 & 17 & 17 & 17 \\
\hline Maximum & 19 & 19 & 20 & 20 & 20 \\
\hline
\end{tabular}

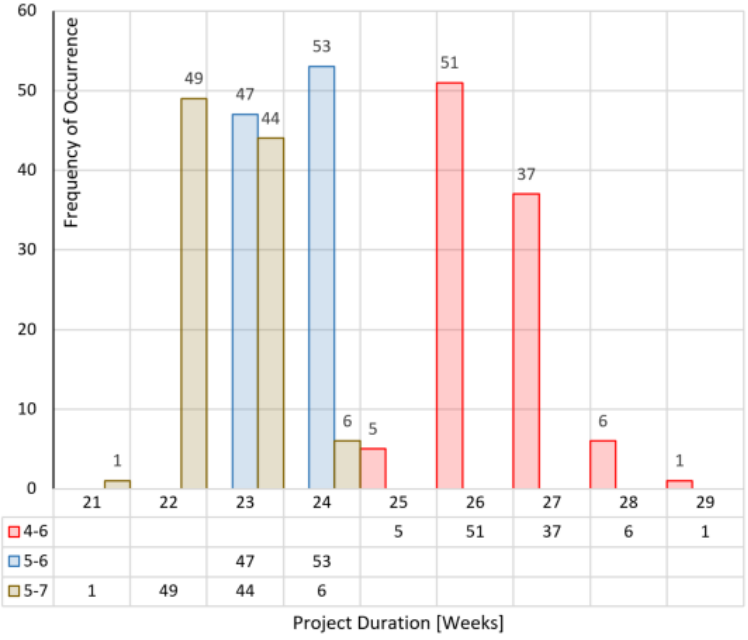

Figure 4: Frequency of Occurrence of Project Duration for Simulated Scenarios 1, 2 , and 3

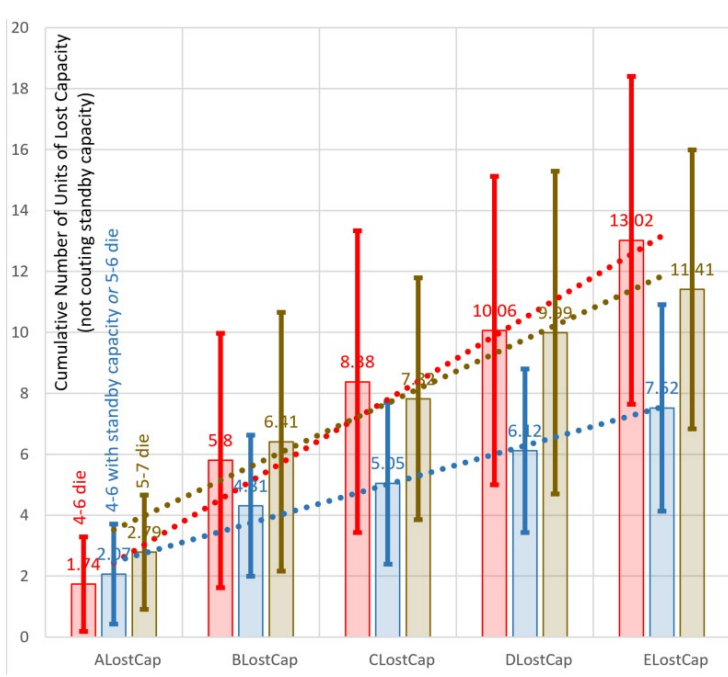

Figure 5: Cumulative Number of Units of Lost Capacity by Trade for Simulated Scenarios 1, 2, and 3 
Figure 3 depicts the results with a box-and-whisker chart for each trade. An " $X$ " marks the mean value. The "box" marks the interquartile range delimited by the upper and lower quartiles (i.e., the percentiles P25 to P75). The lines extending vertically are "whiskers" and extend out another quartile relative to the box. Points further than 1.5 times the length of the box from the whisker mark outliers. Table 1 shows the mean, standard deviation, as well as minimum and maximum values of the same data.

Since the average roll in Scenarios 1, 2, and 3 is respectively 5, 5.5, and 6 units, the average time on site for each trade decreases correspondingly. However, Scenario 2 exhibits the smallest difference in minimum vs. maximum time on site (either 1 or 2 weeks). It has the smallest standard deviation compared trade-by-trade across scenarios, that is, this system is the most stable. For Scenarios 1 and 3, that minimum vs. maximum difference is at least 3 and as much as 5 weeks. Likewise (but not illustrated), considering the inventory buffers that will build up when each scenario plays out, the fluctuations in their size is expected to be less in Scenario 2 than in Scenarios 1 and 3.

In the hypothetical case that trades could always roll the value of their die's average and never have to starve, the computed duration of their time on site in Scenarios 1, 2, and 3 respectively would be 100 units $/ 5$ units/week $=20$ weeks, 100 units/5.5 units/week $=18.18$ weeks ( 19 weeks if rounded up), and 100 units $/ 6$ units/week $=16.67$ weeks $(17$ weeks if rounded up). These durations are indicated with dashed horizontal lines in the color of each scenario in Figure 3. Scenario 2's boxes are closer to that computed value than the boxes for Scenarios 1 and 3 are; the latter all fall above those dashed lines. The likelihood that trades in Scenarios 1 and 3 will have to spend more time (their risk of a loss aka. downside risk) is greater. (Note: this needs further study with a larger number of replications because Trade A's mean value (marked X) would be expected to fall on each of those lines, but it does not in these sample data sets.)

Comparing the maximum values of time on site trade-by-trade, Scenario 1 is worse than the other two in all regards. This should come as no surprise because its trades have less capacity. Scenarios 2 and 3 are closer to each other. Scenario 3 is of course "faster" and may be deemed better in that the average of each trade is lower than it is in Scenario 2. However, it is not better in that each trade has a larger standard deviation.

Both Scenarios 2 and 3 have the same maximum duration (the lowest number on their die is 5); both complete the project in 24 weeks (4 weeks until Trade E mobilizes on site plus the maximum value of Trade E's time on site) as shown in Figure 4. Scenario 3 offers a chance that the project may finish sooner. In risk management, this is called an "upside advantage," but whether it can be taken advantage of in project management is not a given. For example, it depends on if and how resources that are committed to the project but finishing early can be redeployed elsewhere. It also depends on the readiness of the project's customer(s), e.g., even when the opportunity to move in early presents itself, the plan to move personnel to a completed facility may not be adjustable. Instead, from a Lean perspective the advantage is being reliable, i.e., not being too early nor too late. Scenario 2 has that advantage.

Finally, Figure 5 depicts the data collected in the Lostcapacityx queue. It is the capacity that trade $x$ provides each week (not counting standby) but is not able to exercise, accumulated week by week for the duration the trade is on site. This data is depicted by its mean value as a bar in the histogram with a vertical line extending out one standard deviation above it. The data shows that capacity losses increase further down the Parade due to the compounding impact of the manifestation of variability. The dashed lines indicate the trend (for simplicity assumed to be linear) of this increase for each scenario. 
This data is complementary to simulation data previously depicted in Parade papers, that showed the number of units passed by trades decreased further down the Parade. However, by focusing here on the use of standby capacity as a means to mitigate that impact, a number of topics have been broached that warrant discussion.

\section{DISCUSSION}

Standby capacity (or standby resource) is not a common term in construction project management. It is directly related to the concept of underloading, the provision of extra capacity in order to attain the desired level of reliability in meeting a stochastic demand. Thus, how much to underload is a question that loops back to the performance metrics being considered. For example, the Parade with all trades using a 4-6 die but takted at 4 units per week (instead of 5 as in the model) would be $100 \%$ reliable, but 2 units of capacity would be lost each time a 6 is rolled and the project would take 29 weeks to complete. Given that a reason for takting a project (and the Parade of Trades) is the desire to predictably complete the project in terms of cost and time, an argument can be made in favor of this plan.

The use of extra capacity ad hoc in the form of working overtime and overmanning is commonplace in remedial interventions to get project schedules back on track. In contrast, in this paper, we have argued for allocating extra capacity a priori to serve as a buffer in the process of production system design and specifically in the planning stage of a project to gain workflow reliability. The academic and professional literature we are aware of rarely presents the use of standby capacity as an option in construction project planning. However, standby capacity, which is a kind of slack, is described in related literature (e.g., Saurin 2017). The focus of the construction project planning literature appears to be on adding time buffers and (often consequently) inventory buffers. When it is mentioned, standby capacity appears to pertain more to equipment than to other resources. It is possible that the concept is described using a different term (e.g., we did not find even one instance of the use of the term standby, stand-by, or stand by in Goldratt and Cox (1986), though the concept is relevant to their argument). Planning for a resource to be left idle intentionally for some time, is a necessary reality when managing a stochastic system (e.g., when you need an ambulance, you do not want it to be tied up elsewhere).

Providing standby capacity is different from adding capacity. This is clearly illustrated by comparing Scenarios 2 and 3. In Scenario 3 plenty of variability can manifest itself whereas in Scenario 2 the variability is attenuated. If the performance expectation is to pass 5 units / week, then using a 5-7 die means overproducing which is wasteful.

Given the use of a fair 4-6 die, one may expect that any trade's standby resource will be needed roughly $50 \%$ of the time to pass units in the Parade. What will that resource then be doing the other $50 \%$ of the time? We think of standby capacity as the capacity provided by a line supervisor who is at the ready to help when a line worker pulls the andon cord (this may to some degree be what a working foreman in construction does as well). A supervisor not needed to help on the line has time to observe work being done, check whether the standard work is executed as planned, learn whether it is done consistently, provide worker training and professional development, and find ways to improve the work. Using the process capability of the 4-6 die as an example, improvements would aim to reduce the variation around the mean and may lead to a 4-56 die, a 4-5-5-6, etc. until the ideal all-5 is reached. (It would be easy to modify the die in the model to study such scenarios.) 
Academics and industry practitioners alike refer to variability being "inherent" in construction work, but some variability can be harnessed. One way is to improve an operation's design: improve the die first by reducing its standard deviation and then by increasing its average. A second way is to improve the production system's design: e.g., use takt so as to avoid reverberations of delays through the schedule, and other ways exist. A key point of this paper is that the stability that is created by being able to consistently exercise the available capacity helps trades to assess and validate their process capability and this in turn can lead to improvement in overall project performance.

\section{CONCLUSIONS}

This paper addressed the question: How would you takt the Parade of Trades? A reason for takting a project (the Parade) is the desire to predictably complete it in terms of cost and time. Because of variability in the system, cost and time are not deterministic: they are outcomes associated with a degree of likelihood (risk). Eradication of variability is the key to creating predictability; if and where variability remains, buffers may be added to the system to help mitigate its impact on system performance. We presented one way of structuring the Parade's work to lessen the impact of variability in the system, namely using standby capacity as the buffer. Discrete-event simulation then served as a discovery tool to study alternative scenarios within this production system's design.

The paper also addressed the question: What metrics should be applied when gauging the performance of the Parade? In response, simulation data was presented for three metrics: (1) project duration, (2) time on site for each trade, and (3) cumulative lost capacity for each trade. These address concerns about project performance (akin to the value stream) and about trade performance (akin to steps in the value stream). They were selected to spark discussion about the distinction between simply adding capacity vs. providing standby capacity. The latter appears to be more helpful in promoting continuous improvement. In this context, the distinction between capacity and standby capacity offered feedback that can be used to improve process capability.

Many other work structuring scenarios can be developed based on the Parade of Trades. A key is to keep them simple for educational purposes so that the lessons learned from them will be clear. The hope and expectation is that the takted Parade of Trades model will inspire readers to further explore many other alternatives.

\section{ACKNOWLEDGMENTS}

The development of the model described in this paper was supported in part by members of the Project Production Systems Laboratory (P2SL) at UC Berkeley and in part by the National Science Foundation (NSF) under grant number CMMI-1563511. Any opinions, findings, and conclusions or recommendations expressed in this paper are those of the authors and do not necessarily reflect the views of members of P2SL or NSF.

\section{REFERENCES}

Abbasian-Hosseini, S.A., Liu, M., and Howell, G. 2018. "Investigating the Cost-Benefit Trade-Off of Additional Planning using Parade Game Simulation." J. Management in Engineering, 34 (2), doi: 10.1061/(ASCE)ME.1943-5479.0000580

Alarcón, L.F. and Ashley, D.B. 1999. "Playing Games: Evaluating the Impact of Lean Production Strategies on Project Cost and Schedule." Proc. $7^{\text {th }}$ Ann. Conf. Int. Group for Lean Constr., 26-28 July, Berkeley, California, pp. 263-274.

Ballard, G. 1999. "Improving Work Flow Reliability." Proc. $7^{\text {th }}$ Ann. Conf. Int. Group for Lean Constr., 26-28 July, Berkeley, California, USA, pp. 275-286. 
Ballard, G. and Howell, G. 1998. "Shielding Production: Essential Step in Production Control.” J. Constr. Eng. Manage., 10.1061/(ASCE)0733-9364(1998)124:1(11), 11-17.

Crichton, C. (1966). Interdependence and Uncertainty. A Study of the Building Industry. Tavistock Institute, Tavistock Pubs., London.

Dlouhy, J., Binninger, M., and Haghsheno, S. 2019. "Buffer Management in Takt Planning-An Overview of Buffers in Takt Systems." Pasquire, C. and Hamzeh, F.R. (eds.) Proc. $27^{\text {th }}$ Ann. Conf. Int. Group for Lean Constr., Dublin, Ireland, pp. 429-440.

Frandson, A.G., Seppänen, O., and Tommelein, I.D. 2015. "Comparison between Location Based Management and Takt Time Planning." Proc. 23 ${ }^{\text {rd }}$ Ann. Conf. Int. Group for Lean Constr., Perth, Australia, 29-31 July, pp. 3-12.

Goldratt, E.M. and Cox, J. 1986. The Goal. Croton-on-Hudson, NY: North River Press.

González, V., Alarcón, L.F., and Gazmuri, P. 2006. "Design of Work in Process Buffers in Repetitive Building Projects: A Case Study." Proc. $14^{\text {th }}$ Ann. Conf. Int. Group for Lean Constr., Santiago, Chile, pp. 165-176.

Han, S. and Park, M. 2011. "Interactive Parade Game: Impact of Managerial Reactions to Workflow Variability." J. Inf. Technol. Constr., 16, 105-118, online at https://www.itcon.org/papers/2011_7.content.01802.pdf

Hopp, W.J. and Spearman, M.L. 2004. "To Pull or not to Pull: What is the Question?" Manuf. and Service Operations Management, 6 (2) 133-148.

Horman, M. and Kenley, R. 1998. "Process Dynamics: Identifying a Strategy for the Deployment of Buffers in Building Projects." Int. J. of Logistics Research and Applications, 1 (3) 221-237, DOI: 10.1080/13675569808962049

Horman, M.J., Messner, J.I., Riley, D.R., and Pulaski, M.H. 2003. "Using Buffers to Manage Production: A Case Study of the Pentagon Renovation Project." Proc. $11^{\text {th }}$ Ann. Conf. Int. Group for Lean Constr., Virginia, USA.

Howell, G., Laufer, A., and Ballard, G. 1993. "Interaction between Subcycles: One Key to Improved Methods. ” J. Constr. Engin. and Manage, 119 (4) 714-728.

Ioannou, P.G. (n.d.) http://www.ioannou.org/stroboscope/ezstrobe, visited 20 Jan. 2020.

Martinez, J.C. 1996. "STROBOSCOPE State and Resource Based Simulation of Construction Processes." PhD Diss., Civil and Envir. Engrg. Dept., Univ. of Michigan, Ann Arbor, MI.

Modig, N. and Åhlström, P. 2012. This is Lean: Resolving the Efficiency Paradox. Rheologica.

Rother, M. and Shook, J. 2003. Learning to See: Value Stream Mapping to Add Value and Eliminate Muda. Version 1.3, The Lean Enterprise Institute, Cambridge, MA.

Sakamoto, M., Horman, M.J., and Thomas, H.R. 2002. "A Study of the Relationship Between Buffers and Performance in Construction." Formoso, C.T. and Ballard, G., Proc. $10^{\text {th }}$ Conf. Int. Group for Lean Constr., Gramado, Brazil, 6-8 Aug., 577-589.

Saurin, T.A. 2017. "Removing Waste while Preserving Slack: the Lean and Complexity Perspectives." Proc. 25 th Ann. Conf. Int. Group for Lean Constr., Heraklion, Greece, pp. 209-216.

Senior, B.A. 2011. "Enhancing the Construction Parade of Trades Game." Proc. $47^{\text {th }}$ ASC Ann. Int. Conf., Univ. of Nebraska-Lincoln in Omaha, NE.

Tommelein, I.D., Riley, D., and Howell, G.A. 1998. "Parade Game: Impact of Work Flow Variability on Succeeding Trade Performance." Proc. $\sigma^{\text {th }}$ Ann. Conf. Int. Group for Lean Constr., 13-15 August, Guaruja, Brazil, 14 pp.

Tommelein, I.D., Riley, D., and Howell, G.A. 1999. "Parade Game: Impact of Work Flow Variability on Trade Performance.” J. Constr. Engin. Manage., 125(5) 304-310. 